\title{
AS MANIFESTAÇÕES DE GAME DESIGN NAS PESQUISAS ACADÊMICAS QUE RELACIONAM OS JOGOS DIGITIAIS E O ENSINO E A APRENDIZAGEM DE MATEMÁTICA: DEZ ANOS DE ESTUDOS NO BRASIL
}

\author{
Daniel Moreira da Silva \\ Universidade Cruzeiro do Sul/ profdanielmoreira@gmail.com \\ Ismar Frango Silveira \\ Universidade Cruzeiro do Sul/ ismar.silveira@cruzeirodosul.edu.br
}

\section{Resumo}

Os jogos digitais apresentam-se promissores no desenvolvimento de habilidades matemáticas em qualquer etapa da escolarização. Nesse sentido, este artigo busca apresentar um mapeamento do estado da arte, limitado a investigar em teses de doutorado e dissertações de mestrado brasileiras o que emerge a respeito de game design nas pesquisas que tratam de jogos digitais voltados aos processos de ensino e aprendizagem de matemática, no período compreendido entre 2008 a 2018. Observou-se que parte considerável das teses e dissertações investigadas apresentam traços ou elementos de game design na perspectiva de Schell (2008). No entanto, há um predomínio de preocupação dos desenvolvedores de jogos digitais relacionados principalmente aos elementos da Mecânica e Tecnologia. Diante disso, conclui-se que há necessidade de outras investigações na relação de game design para o desenvolvimento de jogos digitais pensados para os processos de ensino e aprendizagem de matemática, considerando, com a mesma relevância, os demais elementos de game design.

Palavras-chave: Educação Matemática, Jogos Digitais, Matemática, Game Design.

\section{Abstract}

Digital games are promising in the development of mathematical skills at any stage of schooling. In this sense, this article seeks to present a SotA (State-of-the-art) mapping, limited to seek, in Brazilian PhD. and MSc. Thesis, which emerges about game design in researches that deal with digital games for mathematics teaching and learning, from 2008 to 2018. It was observed that a good part of the works investigated show traits or elements of game design under Schell's perspective (2008). However, there is a predominance of concern of the developers of digital games mainly regarding elements of Mechanics and Technology. Therefore, it is concluded that there is a need for further investigations in the game design relationship for the development of digital games that aid the processes of 
mathematics teaching and learning, considering, with the same relevance, all other elements of game design.

Keywords: Mathematic Education, Digital Games. Mathematics. Game Design.

\section{Introdução}

O saber matemático é essencial para o desenvolvimento integral do cidadão. Ele está presente em diversas situações do cotidiano, seja no âmbito pessoal ou profissional, seja nas tomadas de decisões, resolução de problemas, avanços nas tecnologias, inovações além das contribuições para a formação de cidadãos críticos, responsáveis por si e por todos. Tais afirmações apoiam-se originalmente nos Parâmetros Curriculares Nacionais (BRASIL, 1998), onde se lê que a Matemática também funciona, além dos pontos aqui mencionados, como instrumento essencial para a construção de conhecimentos em outras áreas curriculares.

A Base Nacional Comum Curricular (BNCC) menciona a "resolução de problemas, de investigação, de desenvolvimento de projetos e da modelagem como formas privilegiadas da atividade matemática" como "objeto e estratégia" para o Ensino fundamental (BRASIL, 2018, p. 264) alinhando os processos de aprendizagem às competências fundamentais do letramento matemático e ao Pensamento Computacional, cujas relações com a Matemática são esmiuçadas por Barcelos et al. (2015).

Contudo, existem grandes desafios quanto ao ensino e a aprendizagem de Matemática. Por um lado, os professores, em tornar o processo do ensino mais atrativo e significativo para seus alunos. Do outro lado, o aluno, em tentar ver as conexões e aplicabilidade do que é ensinado em matemática em seu cotidiano. A matemática trabalhada nas escolas muitas vezes se limita ao campo dos algoritmos e representações algébricas, em que fórmulas e regras são mais importantes para ensinar e aprender do que suas significações para o desenvolvimento do pensamento crítico e resoluções de problemas do cotidiano. Moysés (2001, p. 60) reforça essa ideia, quando diz que "há crescente evidência de que a escolarização está contribuindo muito pouco para o desempenho fora da escola".

Pensando em contribuir nesse processo de aprendizagem dos alunos, em específico no que diz respeito à matemática da Educação Básica, diversas estratégias metodológicas de ensino são frequentemente propostas, considerando o perfil das gerações contemporâneas, as demandas sociais e as contribuições de pesquisas científicas que são apresentadas. Dentre essas propostas, as que envolvem tecnologias digitais ganham espaço nas práticas de ensino. Segundo Pereira et al. (2017, p. 81) a presença das Tecnologias Digitais de Informação e Comunicação (TDIC) na sociedade contemporânea, com atuações em diversas áreas, vêm provocando mudanças no mercado de trabalho e consequentemente no cotidiano das pessoas. $E$ nesse âmbito das tecnologias, é possível destacar os jogos digitais como ferramentas com grandes e inexplorados potenciais para apoio aos processos de ensino e aprendizagem.

Nesse sentido, o uso de jogos digitais na educação vem se mostrando favorável devido ao alto poder motivador, auxiliando no aspecto de atrair a atenção dos jovens 
estudantes, bem como dos adultos, e nas possibilidades de aprendizagem colaborativa. Para Schelemmer e Lopes (2016, p. 185) "os jogos se tornam significativos para os jogadores, principalmente porque possibilitam viver uma experiência capaz de atribuir sentido às informações". Ainda que haja importantes ressalvas no que diz respeito à inadequação de muitos jogos digitais educacionais e à dificuldade de adaptação dos mesmos a diferentes realidades (SILVEIRA e VILLALBA-CONDORI, 2018), ressalta-se aqui principalmente seu caráter motivador, com potencial para promover o engajamento dos estudantes (BARBOZA e SILVEIRA, 2016), quando seu uso é alinhado a estratégias didáticas adequadas (BORBA, SILVA e GADANIDIS, 2018).

Diante disso, observa-se o interesse de acadêmicos (mestrandos e doutorandos) de diversas áreas como Educação, Educação Matemática, Ensino de Ciências, Ciência da Computação entre outras, nos últimos anos, em investigar as potencialidades e possibilidades do uso de jogos digitais nos processos de ensino e aprendizagem da Matemática. No entanto, é possível observar em certos jogos digitais voltados ao ensino e aprendizagem de matemática algumas fragilidades quanto à coerência entre os aspectos de narrativa, mecânica e jogabilidade dos jogos e as habilidades matemáticas a serem desenvolvidas, indicadas na BNCC (BRASIL, 2018).

Segundo a BNCC (MEC, 2018, p. 264), determina que "o Ensino Fundamental deve ter compromisso com o desenvolvimento do letramento matemático". Neste mesmo documento apresenta o entendimento de letramento matemático:

é a capacidade individual de formular, empregar e interpretar a matemática em uma variedade de contextos. Isso inclui raciocinar matematicamente e utilizar conceitos, procedimentos, fatos e ferramentas matemáticas para descrever, explicar e predizer fenômenos. Isso auxilia os indivíduos a reconhecer o papel que a matemática exerce no mundo e para que cidadãos construtivos, engajados e reflexivos possam fazer julgamentos bem fundamentados e tomar as decisões necessárias (BRASIL, 2018, p. 264).

Diante desses pontos destacados, propõe-se o presente mapeamento do estado da arte, apresentando as pesquisas acadêmicas em âmbito nacional (teses e dissertações) que envolvem, de alguma forma, os processos de game design nas pesquisas que tratam da relação entre jogos digitais e a matemática. Fez-se o recorte do período de 2008 a 2018, no Brasil. Antes de apresentar os resultados desse mapeamento, este artigo traz uma breve conceituação a respeito de jogos digitais e game design. Em seguida, é feita a apresentação da metodologia de pesquisa, dos resultados e análises, concluindo com as considerações finais.

\section{Jogos Digitais e Game Design}

Apresentar o conceito de jogos digitais e suas potencialidades pode colaborar na compreensão dos focos temáticos que serão identificados nas dissertações e teses investigadas. Nesse sentido, no que se refere às potencialidades dos jogos digitais como motores de motivação, Petry (2016, p. 25) destaca que "todos os elementos presentes no jogo - regras, conflitos, objetivos, definição de pontos e tomadas de decisões - são 
elementos constituintes da vida humana em geral". Diante disso, é possível compreender que essa ideia sugere que os jogos têm potencial para suportar processos de aprendizagem significativa, entre os quais aqueles a promover o letramento matemático.

Kirriemuir e Mcfarlane (2004) definem um jogo digital:

como programas que operam nas plataformas como hardware, conhecido como videogame consoles (exemplo o Playstation, Xbox etc..) que operação com apoio de uma televisão, por computadores pessoais, por dispositivos móveis, além de fornecer alguma informação digital visual ou substância para um ou mais jogadores, leva alguma interação entre jogadores, processa a interação de acordo com um conjunto das regras do jogo programado e altera a informação digital fornecida para os jogadores (tradução nossa).

Quanto a definição de jogo digital, Petry (2016) determina suas características:

(1) liberdade, (2) regras, (3) produção de um estado de ânimo, (4) capacidade de modificação de regras durante o processo do jogo, (5) a possível existência de elementos antagônicos (conflitos) que estimulem os jogadores a superá-los, (6) objetivos intrínsecos ao jogo ou formulados pelos jogadores, (7) a circunscrição de pontos de partida e pontos de final do jogo, bem como (8) a possibilidade da tomada de decisões por parte do jogador - formam também uma estrutura ontológica que torna o jogo digital um objeto singular na cultura contemporânea (PETRY, 2016, p.40).

Portanto, os jogos digitais favorecem na interação entre os jogadores, no dinamismo, em atrair a atenção dos jovens estudantes, além de colaborar no desenvolvimento da aprendizagem.

No que se refere ao processo de game design, Schell (2008, p.41-42), destaca quatro elementos básicos que o constituem:

Mecânica: Estes são os procedimentos e regras do seu jogo. A Mecânica descreve os objetivos do jogo, o que os jogadores podem e não podem fazer no jogo e o que acontece quando eles tentam.

Narrativa: É a história: Esta é a sequência de eventos que se desdobra no jogo. Pode ser linear e pré-formatado ou pode ser ramificado e emergente.

Estética: é um aspecto incrivelmente importante do design de jogos, uma vez que o relacionamento mais direto com a experiência de um jogador.

Tecnologia: é essencialmente, pois é nela o meio no qual a estética acontece, na qual a mecânica irá ocorrer e através do qual a história será contada (tradução nossa). 
Diante disso, percebe-se que não é um processo trivial o desenvolvimento de jogos digitais. No que diz respeito a jogos digitais com propósitos educacionais, outros níveis de complexidade são agregados (SILVEIRA e VILLALBA-CONDORI, 2018).

\section{Procedimentos Metodológicos}

A pesquisa, de natureza bibliográfica (Marconi e Lakatos, 2010) realizada caracteriza-se como Estado da Arte ou do Conhecimento (ROMANOWSKI E ENS, 2006), visto que in lócus de pesquisa se limitou ao banco do catálogo de teses e dissertações da Coordenação de Aperfeiçoamento de Pessoal de Nível Superior (CAPES). Esse mapeamento (BIEMBENGUT, 2008) procurou responder a indagações como: quais os elementos de game design emergem das pesquisas acadêmicas (teses e dissertações) que tratam da relação entre jogos digitais e o ensino e aprendizagem de matemática no período de 2008 a 2018 no contexto brasileiro. Nessa busca pelos elementos de game design nas publicações acadêmicas, busca atender, nesse processo de mapeamento, o que Biembengut (2008) denomina de "traço", entendido como a menor unidade identificável em uma estrutura (BIEMBENGUT, 2008, p. 54).

Para Biembengut $(2008$, p. 74$)$ o mapeamento na pesquisa educacional pode ser abordado sob dois enfoques:

O primeiro consiste em mapear, ou seja, organizar os dados ou entes de forma harmônica de maneira a oferecer um quadro completo deles, uma representação, um mapa onde conste o que for significativo e relevante. O segundo, mais completo, além da organização dos dados ou entes da pesquisa, consiste em compreendê-los em sua estrutura e em seus traços. Ou seja, trata-se de reconhecer padrões, evidências, traços comuns ou peculiares [...].

Para Romanowski e Ens (2006) uma pesquisa do tipo estado da arte, são necessários os seguintes procedimentos dos quais, para buscar as respostas foca-se em: (1) definir o lócus de pesquisa; (2) determinar os descritores; (3) definir a período para consulta; (4) estabelecer os critérios para seleção dos trabalhos acadêmicos; (5) coleta e leitura do resumo das publicações; (6) categorizar os focos temáticos; e (7) identificar as metodologias de pesquisa adotadas para nesses trabalhos.

No contexto deste trabalho, determinaram-se os seguintes descritores: "matemática AND jogos AND digitais", "matemática AND games", "matemática AND games AND design" e "matemática AND jogos AND digitais AND design". Ao aparecer a relação de todas as publicações apresentadas pelo banco da Capes, em primeiro lugar, foi selecionado no filtro somente teses e dissertações, na qual resultou nas respectivas quantidades de publicações por descritores: 100, 549, 42 e 15. Nesse mesmo filtro, foi determinado o período de 2008 a 2018 para análise das publicações.

Para selecionar os trabalhos, definiu-se que no título precisaria aparecer um dos conjuntos de termos: "Matemática" e "Jogos Digitais", "Matemática" e "Games" ou, pelo 
menos, palavras que indicassem uma abordagem para ensino $u$ aprendizagem matemática por meio de jogos digitais. Em diversos momentos, para os trabalhos em cujos títulos constavam as palavras "matemática" e "jogos", foi necessário ler o resumo para identificar se o trabalho referia-se a jogos digitais ou físicos. Não se delimitou a área de conhecimento, na busca do banco da Capes, devido a perceber-se, durante os resultados das pesquisas, a restrita quantidade de teses disponíveis diante do critério definido para o título.

$\mathrm{Na}$ segunda etapa, pelas buscas das dissertações, observaram-se mais publicações, no entanto, também, não se delimitou a área. A partir dos resultados, foi realizada a leitura dos resumos com a intenção de buscar os elementos de design de jogos presentes nas pesquisas adotadas. No entanto, por diversas vezes, houve necessidade de leitura de outras partes dos textos, dessas teses e dissertações, devido ao fato do resumo apenas não responder por completo às indagações deste trabalho.

\section{Resultados e Análises}

Das 83 publicações de teses que apareceram no Banco de Catálogo da Capes (com repetições, visto que algumas publicações se repetiam para descritores diferentes) somente 6 continham no título as palavras "matemática" e "jogos digitais" ou "games". Isso constituiu a tabela 1. Conforme Romanowski (2006) orienta, e considerando a quantidade de teses encontradas, é que decide-se por elaborar uma síntese preliminar, considerando o tema, os objetivos, as problemáticas e as metodologias. Nesse sentido, no que se refere aos resultados e análises, decidiu-se organizar esse mapeamento pelo primeiro enfoque sugerido por Biembengut (2008). Para tanto, foi organizado um quadro com informações dos trabalhos como o título, a área e a instituição, além do ano da pesquisa, para perceber as influências nas escolhas das teses e dissertações. Em seguida, descrevem-se os objetivos dos trabalhos, tecendo as manifestações de game design, devido à baixa quantidade encontrada. Enquanto que nas dissertações, pelo número destas definidas para análise, buscou-se identificar nas estruturas os entes (objetos, coisas, substâncias) e as relações entre eles e, nos traços, as características ou vestígios destes entes (BIEMBUNGUT, 2008), para descrever os elementos de game design presentes.

Quadro 1: Teses resultantes do banco de teses da Capes

\begin{tabular}{|c|c|c|c|c|c|}
\hline ID & Título & Área & Autor & Instituição & Ano \\
\hline 1 & $\begin{array}{l}\text { Saberes Docentes para } \\
\text { Promoção de } \\
\text { Aprendizagem em } \\
\text { Ciências e Matemática a } \\
\text { partir do } \\
\text { Desenvolvimento de } \\
\text { Jogos Digitais }\end{array}$ & $\begin{array}{l}\text { Educação em } \\
\text { Ciências e Saúde }\end{array}$ & $\begin{array}{l}\text { MARINHO, } \\
\text { Fernando Celso } \\
\text { Villar. }\end{array}$ & $\begin{array}{l}\text { Universidade } \\
\text { Federal do Rio de } \\
\text { Janeiro }\end{array}$ & 2014 \\
\hline 2 & $\begin{array}{l}\text { Relações entre o } \\
\text { Pensamento } \\
\text { Computacional e a } \\
\text { Matemática em } \\
\text { atividades didáticas de } \\
\text { construção de jogos }\end{array}$ & Ensino de Ciências & $\begin{array}{l}\text { BARCELOS, } \\
\text { Thiago } \\
\text { Schumacher. }\end{array}$ & $\begin{array}{l}\text { Universidade } \\
\text { Cruzeiro do Sul }\end{array}$ & 2014 \\
\hline
\end{tabular}




\begin{tabular}{|c|c|c|c|c|c|}
\hline & digitais & & & & \\
\hline 3 & $\begin{array}{l}\text { A experiência } \\
\text { matemática no Universo } \\
\text { dos jogos digitais: } 0 \\
\text { processo de jogar e o } \\
\text { raciocínio lógico e } \\
\text { matemático }\end{array}$ & $\begin{array}{l}\text { Educação } \\
\text { Matemática }\end{array}$ & $\begin{array}{l}\text { TONEIS, Cristiano } \\
\text { Natal. }\end{array}$ & $\begin{array}{l}\text { Universidade } \\
\text { Anhanguera de São } \\
\text { Paulo }\end{array}$ & 2015 \\
\hline 4 & $\begin{array}{l}\text { Produção de Jogos } \\
\text { Digitais por Jovens: Uma } \\
\text { possibilidade de } \\
\text { Interação com a } \\
\text { Matemática }\end{array}$ & Educação & $\begin{array}{l}\text { SILVA, Jean Carlo } \\
\text { da. }\end{array}$ & $\begin{array}{l}\text { Universidade } \\
\text { Federal de } \\
\text { Uberlândia }\end{array}$ & 2016 \\
\hline 5 & $\begin{array}{l}\text { Método de Concepção } \\
\text { de Serious Game para } \\
\text { Avaliar Conceitos } \\
\text { Básicos de Matemática } \\
\text { de Alunos com Falta de } \\
\text { Atenção }\end{array}$ & $\begin{array}{l}\text { Engenharia } \\
\text { Biomédica }\end{array}$ & $\begin{array}{l}\text { IANAGUIVARA, } \\
\text { Eduardo Seige. }\end{array}$ & $\begin{array}{l}\text { Universidade de } \\
\text { Mogi das Cruzes }\end{array}$ & 2016 \\
\hline 6 & $\begin{array}{l}\text { Uso de Jogos Digitais no } \\
\text { Desenvolvimento de } \\
\text { Competências } \\
\text { Curriculares da } \\
\text { Matemática }\end{array}$ & $\begin{array}{l}\text { Ciência da } \\
\text { Computação }\end{array}$ & $\begin{array}{l}\text { PEREIRA, } \\
\text { Adalberto Bosco } \\
\text { Castro. }\end{array}$ & $\begin{array}{l}\text { Universidade de } \\
\text { São Paulo }\end{array}$ & 2017 \\
\hline
\end{tabular}

Fonte: elaborado pelos próprios autores.

Diante disso, na primeira tese (1), Marinho (2014) teve como foco a reflexão sobre os saberes docentes para o uso de jogos digitais na educação básica. Portanto, teve como objetivo estudar os saberes para adoção de uma proposta pedagógica de ensino e aprendizagem de ciências e matemática baseada desenvolvimento de jogos digitais na educação básica. Então, por meio da criação de um curso que serviu de contexto (material, processos, tecnologias) para identificar conhecimentos tecnológicos necessários e os saberes mobilizados pelos professores no planejamento de uma proposta pedagógica, buscou-se apresentar aspectos importantes para 0 desenvolvimento de jogos no campo do ensino e aprendizagem de ciências e matemática. Nesta tese, o que se observa é que alguns traços de game design como a Mecânica, a Estética e a Tecnologia estão presente, porém isto aparece de forma intuitiva, mas não planejada na forma como descreve Schell (2008).

$\mathrm{Na}$ segunda tese (2), Barcelos (2014) teve por objetivo evidenciar quais competências e habilidades da Matemática e do Pensamento Computacional podem ser mobilizadas e desenvolvidas por alunos em atividades didáticas que envolvam a construção de jogos. Um mapeamento de competências comuns ao Pensamento Computacional e à Matemática é apresentado. É então proposta uma Oficina de Produção de Jogos Digitais, inspirada por princípios do construcionismo de Papert e Harel e da Aprendizagem Baseada em Problemas (ABP), com o objetivo de desenvolver competências e habilidades do Pensamento Computacional relacionadas à programação e mobilizar alguns conteúdos da Matemática do ensino médio. Nessa pesquisa observase o trabalho de investigação por meio da análise documental das diretrizes curriculares para o ensino de Matemática no Brasil e no Chile e sua associação com as definições de Pensamento Computacional expressas na literatura. É possível observar na tese a presença do termo "design de interação", indicando traços do elemento de mecânica, como também dos demais elementos comentador por Schell (2008). 
$\mathrm{Na}$ terceira tese (3), Toneis (2015) teve por objetivo identificar e analisar as ações dos jogadores de um game, elaborado pelo próprio autor, diante de puzzles criados para o desenvolvimento do raciocínio lógico e matemático. Diante da imersão e exploração desse jogo, foi investigado se e quais experiências matemáticas emergiram nesse ato de jogar. O autor explicita sua inspiração para criação de diversos elementos que constituem o seu jogo digital, baseado em experiências em contato com histórias mitológicas e épicas, além de jogos como os Role Playing Games (RPG). Além disso, é apontado o potencial dos jogos para o desenvolvimento de conhecimento. Neste trabalho o autor faz o uso de Game Design Document (GDD), em que reúne toda a documentação para a produção de um game, tais como: roteiro; concept art; personagens, modelos e referências. Em consequência disso, percebe os elementos de game design apontados por Schell (2008).

Na quarta tese (4) o autor (SILVA, 2016) busca entender como ocorre a produção de jogos digitais pelos alunos do Curso Técnico em Manutenção e Suporte em Informática integrado ao Ensino Médio de um Instituto Federal de Educação, Ciência e Tecnologia no processo de interação com a Matemática. Embasado na teoria histórico-cultural de Vygotsky, a interação com a Matemática a partir de novas metodologias de ensino é o objeto de pesquisa, tendo como foco o desenvolvimento coletivo de jogos virtuais como instrumento facilitador da aprendizagem da Matemática, o que define, efetivamente, o problema de pesquisa. Dentro dessa análise, um dos eixos verifica a Produção de Jogos Digitais (dividido em: - Parte 1 - Jogos Digitais e Formação Tecnológica e Parte 2 - Jogos Digitais e Aprendizagem da Matemática). Nesse trabalho, são apresentados os elementos de game design devido à construção de jogos, embasados pelos princípios da Semiótica, segundo os pesquisadores.

Na quinta tese (5) encontrada, lanaguivara (2016) teve como objetivo desenvolver e validar um método para concepção de um "serious game" que contemplasse as etapas do processo de desenvolvimento de jogos comerciais e as etapas do desenvolvimento de um serious game integradas com as características do TDAH (Transtorno do Distúrbio de Atenção e Hiperatividade). Um jogo-teste foi desenvolvido para a validação das etapas de desenvolvimento do método e avaliada sobre três elementos: o educacional, o psicológico e o computacional. Foram selecionados 3 professores para o teste educacional (2 do ensino superior e 1 do ensino fundamental - ciclo I), 3 professoras de psicologia para 0 teste psicológico, 3 professores de desenvolvimento de software e 3 professores de desenvolvimento de jogos para contemplar os testes computacionais. Este trabalho apresenta claros elementos de game design, em se tratando dos métodos, como exemplo - SeGAE (Serious Game Authoring Enviroment) que permite desde as edições do "avatar" até os objetivos das missões e condições de derrota/vitória. Também apresenta uma tabela de objetivos da aprendizagem, bem com a tabela de relacionamento entre as competências, habilidades e desafios do jogo, da relação entre os desafios e o conteúdo educacional e objetivos educacionais. Isso sugere que contempla os aspectos da mecânica e narrativa sugeridos por Schell (2008).

Por fim, na sexta e última tese (6), Pereira (2017) investiga a mediação dos jogos digitais em conjunto com um instrutor no contexto da sala de aula e da formação do professor, com base em experimentos em uma escola estadual de tempo integral, situada 
em Cotia - São Paulo. Neste trabalho, são determinados alguns jogos digitais para observar a relação do jogo com os conteúdos curriculares de Matemática. Nesse trabalho há pouco tratamento direto de game design, focando nas contribuições que os jogos favorecem no desenvolvimento das competências de aprendizagem em matemática. No entanto, há traços dos elementos que constituem o game design, de forma intuitiva e não com o rigor ao desenvolver um jogo digital.

Em se tratando das dissertações pesquisadas, em um universo de 629, apenas 59 se mostravam contemplar os requisitos das escolhas, seguindo os critérios. No entanto, ao ler os respectivos resumos, somente 39 efetivamente foram selecionadas para realizar a análise, sintetizada nono Quadro 2 a seguir. É importante ressaltar que, dentre os descritos, somente uma dissertação não apresenta os critérios para a escolha dos trabalhos. Essa pesquisa, denominada "Critérios de Decisão e Games em Sala de Aula", origina-se da área de Ensino de Ciências e Matemática. Isso influenciou na decisão da sua escolha, também, após ler o respectivo resumo.

Quadro 2: Dissertações resultantes do banco de dissertações da Capes

\begin{tabular}{|c|c|c|c|c|c|}
\hline ID & Título & Área & Autor & Instituição & Ano \\
\hline 1 & $\begin{array}{l}\text { A lógica da descoberta } \\
\text { nos jogos digitais }\end{array}$ & $\begin{array}{l}\text { Tecnologias da } \\
\text { Inteligência e Design } \\
\text { Digital }\end{array}$ & $\begin{array}{l}\text { TONÉIS, Cristiano } \\
\text { Natal }\end{array}$ & $\begin{array}{l}\text { Pontifícia Universidade } \\
\text { Católica de São Paulo }\end{array}$ & 2010 \\
\hline 2 & $\begin{array}{l}\text { Os games e as funções } \\
\text { matemática: uma } \\
\text { aplicabilidade do Tribal } \\
\text { Wars no cotidiano } \\
\text { escolar do ensino médio }\end{array}$ & $\begin{array}{l}\text { Ensino de Ciências e } \\
\text { Matemática }\end{array}$ & $\begin{array}{l}\text { ARAÚJO, Fábio } \\
\text { Ferreira Nunes de. }\end{array}$ & $\begin{array}{l}\text { Universidade Estadual } \\
\text { da Paraíba. }\end{array}$ & 2010 \\
\hline 3 & $\begin{array}{l}\text { As Contribuições da } \\
\text { Construção de Jogos } \\
\text { Eletrônicos para a } \\
\text { Formação Matemático- } \\
\text { Pedagógico-Tecnológica } \\
\text { de Professores das } \\
\text { Séries Iniciais do Ensino } \\
\text { Fundamental }\end{array}$ & $\begin{array}{l}\text { Ensino de Ciências e } \\
\text { Matemática }\end{array}$ & $\begin{array}{l}\text { SOUZA JR., } \\
\text { Manoel Batista. }\end{array}$ & $\begin{array}{l}\text { Universidade Luterana } \\
\text { do Brasil }\end{array}$ & 2010 \\
\hline 4 & $\begin{array}{l}\text { O uso do Software de } \\
\text { Autoria JCLIC como } \\
\text { Ferramenta Pedagógica } \\
\text { no Processo de Ensino- } \\
\text { Aprendizagem de } \\
\text { Conteúdos da } \\
\text { Matemática nas Séries } \\
\text { Finais do Ensino } \\
\text { Fundamental por Meio } \\
\text { da Construção de Jogos } \\
\text { Educativos }\end{array}$ & $\begin{array}{l}\text { Ensino de Ciências e } \\
\text { Matemática }\end{array}$ & $\begin{array}{l}\text { SILVA, Jose } \\
\text { Claudio Moreira } \\
\text { da. }\end{array}$ & $\begin{array}{l}\text { Universidade Federal } \\
\text { do Ceará }\end{array}$ & 2013 \\
\hline 5 & $\begin{array}{l}\text { Jogos Eletrônicos } \\
\text { Gratuitos para o Ensino } \\
\text { da Matemática: } \\
\text { Levantamento e } \\
\text { Proposta de um } \\
\text { Recurso Didático }\end{array}$ & Ensino das Ciências & $\begin{array}{l}\text { FLORET, Helder } \\
\text { Franca }\end{array}$ & $\begin{array}{l}\text { Universidade do Grande } \\
\text { Rio }\end{array}$ & 2013 \\
\hline 6 & $\begin{array}{l}\text { Jogos Digitais no Ensino } \\
\text { de Matemática - O } \\
\text { Desenvolvimento de um } \\
\text { Instrumento de Apoio } \\
\text { Diagnóstico das } \\
\text { Concepções dos Alunos } \\
\text { sobre Diferentes } \\
\text { Representações dos } \\
\text { Números }\end{array}$ & $\begin{array}{l}\text { Educação para a } \\
\text { Ciência }\end{array}$ & $\begin{array}{l}\text { MAZIVIERO, Hélio } \\
\text { Fernando Gomes. }\end{array}$ & $\begin{array}{l}\text { Universidade Est. } \\
\text { Paulista Júlio de } \\
\text { Mesquita Filho }\end{array}$ & 2013 \\
\hline
\end{tabular}




\begin{tabular}{|c|c|c|c|c|c|}
\hline 7 & $\begin{array}{l}\text { Matemática, internet e } \\
\text { jogos de lógica, uma } \\
\text { combinação possível }\end{array}$ & $\begin{array}{l}\text { Matemática em Rede } \\
\text { Nacional }\end{array}$ & $\begin{array}{l}\text { BAIROS, Maurício } \\
\text { da Gama. }\end{array}$ & $\begin{array}{l}\text { Universidade Federal } \\
\text { de São João Del-Rei }\end{array}$ & 2015 \\
\hline 8 & $\begin{array}{l}\text { O processo de criação } \\
\text { de um jogo com o } \\
\text { auxílio de recursos } \\
\text { computacionais que } \\
\text { relaciona progressões } \\
\text { aritmética e funções } \\
\text { lineares }\end{array}$ & $\begin{array}{l}\text { Matemática em Rede } \\
\text { Nacional }\end{array}$ & $\begin{array}{l}\text { POLONIO, Rafael } \\
\text { Jose } \\
\text { Dombrauskas. }\end{array}$ & $\begin{array}{l}\text { Universidade de São } \\
\text { Paulo }\end{array}$ & 2015 \\
\hline 9 & $\begin{array}{l}\text { O uso de jogos do } \\
\text { software educativo } \\
\text { Hércules e Jiló no } \\
\text { mundo da matemática } \\
\text { na construção do } \\
\text { conceito de número por } \\
\text { estudantes com } \\
\text { deficiência intelectual }\end{array}$ & Educação & $\begin{array}{l}\text { ROLIM, Cristiane } \\
\text { Ferreira }\end{array}$ & Universidade de Brasília & 2015 \\
\hline 10 & $\begin{array}{l}\text { Um Jogo Computacional } \\
\text { como Proposta para o } \\
\text { Estudo de Funções }\end{array}$ & $\begin{array}{l}\text { Ensino de Ciências e } \\
\text { Tecnologia }\end{array}$ & $\begin{array}{l}\text { ADAMOWICZ, } \\
\text { Bruna Elizabeth }\end{array}$ & $\begin{array}{l}\text { Universidade } \\
\text { Tecnológico Federal do } \\
\text { Paraná }\end{array}$ & 2015 \\
\hline 11 & $\begin{array}{l}\text { Jogos Digitais e o } \\
\text { Ensino de Matemática a } \\
\text { Partir dos Estilos de } \\
\text { Aprendizagem de Felder }\end{array}$ & $\begin{array}{l}\text { Ciências e } \\
\text { Tecnologias na } \\
\text { Educação }\end{array}$ & $\begin{array}{l}\text { CARVALHO, } \\
\text { Carmen Horacina } \\
\text { da Silva }\end{array}$ & $\begin{array}{l}\text { Instituto Federal de } \\
\text { Educ. Ciências e Tecn. } \\
\text { Sul-Rio-Grandense }\end{array}$ & 2016 \\
\hline 12 & $\begin{array}{l}\text { Avançado com } \\
\text { Matemática! Um Jogo } \\
\text { Computacional para } \\
\text { Alunos do Quinto Ano } \\
\text { do Ensino Fundamental } \\
\text { Duque de Caxias } 2016\end{array}$ & Ensino das Ciências & $\begin{array}{l}\text { FERREIRA, Aline } \\
\text { Pereira de Queiroz }\end{array}$ & $\begin{array}{l}\text { Universidade do Grande } \\
\text { Rio }\end{array}$ & 2016 \\
\hline 13 & $\begin{array}{l}\text { Jogos pedagógicos } \\
\text { digitais na formação } \\
\text { inicial de professores } \\
\text { que ensinam } \\
\text { matemática nas séries } \\
\text { iniciais do Ensino } \\
\text { Fundamental }\end{array}$ & $\begin{array}{l}\text { Ensino de Ciências e } \\
\text { Matemática }\end{array}$ & $\begin{array}{l}\text { BRITO, Alan de } \\
\text { Santana }\end{array}$ & $\begin{array}{l}\text { Universidade Cruzeiro } \\
\text { do Sul }\end{array}$ & 2016 \\
\hline 14 & $\begin{array}{l}\text { Desenvolvimento e } \\
\text { avaliação de um jogo de } \\
\text { dominó digital adaptado } \\
\text { para ensino de relações } \\
\text { condicionais } \\
\text { matemáticas }\end{array}$ & $\begin{array}{l}\text { Análise do } \\
\text { Comportamento }\end{array}$ & GRIS, Gabriele & $\begin{array}{l}\text { Universidade Estadual } \\
\text { de Londrina }\end{array}$ & 2016 \\
\hline 15 & $\begin{array}{l}\text { Ensino de Estatística } \\
\text { por meio de jogos }\end{array}$ & Ensino de Matemática & $\begin{array}{l}\text { JUSTO, Ana Olivia } \\
\text { Ramos Pires }\end{array}$ & $\begin{array}{l}\text { Universidade de São } \\
\text { Paulo }\end{array}$ & 2017 \\
\hline 16 & $\begin{array}{l}\text { Criação e Adaptação de } \\
\text { Jogos para o Geogebra }\end{array}$ & $\begin{array}{l}\text { Matemática em Rede } \\
\text { Nacional }\end{array}$ & $\begin{array}{l}\text { PINHEIRO, Paulo } \\
\text { Geovane Ramalho }\end{array}$ & $\begin{array}{l}\text { Universidade Federal } \\
\text { dos Vales do } \\
\text { Jequitinhonha e Mucuri }\end{array}$ & 2017 \\
\hline 17 & $\begin{array}{l}\text { Critérios de Decisão e } \\
\text { Games em Sala de Aula }\end{array}$ & $\begin{array}{l}\text { Ensino de Ciências e } \\
\text { Matemática }\end{array}$ & $\begin{array}{l}\text { NASCIMENTO, } \\
\text { Tatiane Santos } \\
\text { Xavier do. }\end{array}$ & $\begin{array}{l}\text { Universidade Estadual } \\
\text { de Campinas }\end{array}$ & 2017 \\
\hline 18 & $\begin{array}{l}\text { Transposição de Jogos } \\
\text { de Tabuleiro Utilizados } \\
\text { no ensino de } \\
\text { Matemática para o } \\
\text { Formato Digital. }\end{array}$ & Mídia e Tecnologia & $\begin{array}{l}\text { CAMPANA, } \\
\text { Samanta Bueno } \\
\text { de Camargo }\end{array}$ & $\begin{array}{l}\text { Universidade Estadual } \\
\text { Paulista Júlio de } \\
\text { Mesquita Filho }\end{array}$ & 2017 \\
\hline 19 & $\begin{array}{l}\text { A Interatividade dos } \\
\text { Jogos Digitais na } \\
\text { Aprendizagem } \\
\text { Matemática: Uma } \\
\text { decisão em } \\
\text { Neurociência. }\end{array}$ & Educação & $\begin{array}{l}\text { SILVA, Sindia } \\
\text { Liane Demartini } \\
\text { da. }\end{array}$ & $\begin{array}{l}\text { Universidade Federal } \\
\text { da Fronteira Sul }\end{array}$ & 2017 \\
\hline 20 & $\begin{array}{l}\text { Uso de jogos digitais } \\
\text { como artefatos para o } \\
\text { ensino de função do } \\
\text { primeiro e segundo } \\
\text { graus }\end{array}$ & $\begin{array}{l}\text { Ensino de Ciências e } \\
\text { Matemática }\end{array}$ & $\begin{array}{l}\text { GAMA, Rodrigo } \\
\text { Farias }\end{array}$ & $\begin{array}{l}\text { Universidade Federal } \\
\text { de Pelotas }\end{array}$ & 2017 \\
\hline
\end{tabular}




\begin{tabular}{|c|c|c|c|c|c|}
\hline 21 & $\begin{array}{l}\text { Estudo sobre as } \\
\text { Potencialidades do Jogo } \\
\text { Digital Minecraft para o } \\
\text { Ensino de } \\
\text { Proporcionalidade e } \\
\text { tópicos de Geometria. }\end{array}$ & Educação Matemática & $\begin{array}{l}\text { SILVA, Hudson } \\
\text { William da. }\end{array}$ & $\begin{array}{l}\text { Pontifícia Universidade } \\
\text { Católica de São Paulo }\end{array}$ & 2017 \\
\hline 22 & $\begin{array}{l}\text { Jogos digitais } \\
\text { educativos e o ensino } \\
\text { da matemática: } \\
\text { diferentes olhares e } \\
\text { experiências }\end{array}$ & $\begin{array}{l}\text { Educação, Cultura e } \\
\text { Comunicação }\end{array}$ & $\begin{array}{l}\text { TATAGIBA, } \\
\text { Jocilea de Souza. }\end{array}$ & $\begin{array}{l}\text { Universidade do Estado } \\
\text { do Rio de Janeiro }\end{array}$ & 2017 \\
\hline 23 & $\begin{array}{l}\text { Aplicativos do Sistema } \\
\text { Operacional Android na } \\
\text { Aprendizagem de } \\
\text { Matemática: Aplicativos } \\
\text { e Jogos Digitais }\end{array}$ & $\begin{array}{l}\text { Ensino de Ciências e } \\
\text { Matemática }\end{array}$ & $\begin{array}{l}\text { GOMES, Leonardo } \\
\text { Augusto de } \\
\text { Figueiredo. }\end{array}$ & $\begin{array}{l}\text { Universidade Estadual } \\
\text { da Paraíba }\end{array}$ & 2017 \\
\hline 24 & $\begin{array}{l}\text { Ensino de matemática e } \\
\text { jogos digitais: um estudo } \\
\text { etnomatemático nos } \\
\text { anos iniciais }\end{array}$ & $\begin{array}{l}\text { Ensino de ciências } \\
\text { exatas }\end{array}$ & $\begin{array}{l}\text { BERNSTEIN, } \\
\text { Tatiane Cristine }\end{array}$ & $\begin{array}{l}\text { Fundacao Vale do } \\
\text { Taquari de Educacao e } \\
\text { Desenvolvimento Social } \\
\text { - FUVATES }\end{array}$ & 2017 \\
\hline 25 & $\begin{array}{l}\text { Construção de } \\
\text { Conhecimento } \\
\text { Matemático a partir da } \\
\text { Produção de Jogos } \\
\text { Digitais em um Ambiente } \\
\text { Construcionista de } \\
\text { Aprendizagem: } \\
\text { Possibilidades e Desafios }\end{array}$ & $\begin{array}{l}\text { Educação em ciências } \\
\text { e matemática }\end{array}$ & $\begin{array}{l}\text { AZEVEDO, } \\
\text { Greiton toledo de. }\end{array}$ & $\begin{array}{l}\text { Universidade Federal } \\
\text { de Goiás }\end{array}$ & 2017 \\
\hline 26 & $\begin{array}{l}\text { Análise do Currículo e o } \\
\text { uso de Jogos Online } \\
\text { durante o processo de } \\
\text { ensino-aprendizagem, } \\
\text { em ciências e } \\
\text { matemática, nos anos } \\
\text { iniciais do ensino } \\
\text { fundamental }\end{array}$ & Ensino de Ciências & $\begin{array}{l}\text { FARIAS, Rita } \\
\text { Angelita de. }\end{array}$ & $\begin{array}{l}\text { Universidade Cruzeiro } \\
\text { do Sul }\end{array}$ & 2017 \\
\hline 27 & $\begin{array}{l}\text { Elaboração e } \\
\text { Desenvolvimento de } \\
\text { Jogo Matemático para } \\
\text { Aplicações Web Mobile } \\
\text { como Auxilio dos } \\
\text { Processos e da } \\
\text { Matemática Financeira }\end{array}$ & Computação Aplicada & $\begin{array}{l}\text { NUNES, Mônica } \\
\text { de Sousa Viegas }\end{array}$ & $\begin{array}{l}\text { Universidade Estadual } \\
\text { do Ceará }\end{array}$ & 2017 \\
\hline 28 & $\begin{array}{l}\text { O Ensino de } \\
\text { Matemática, a } \\
\text { Neurociência e os } \\
\text { Games: Desafios e } \\
\text { Possibilidades }\end{array}$ & $\begin{array}{l}\text { Ensino de Ciências e } \\
\text { Educação Matemática }\end{array}$ & $\begin{array}{l}\text { CAVALCANTE, } \\
\text { Marlon Rardelly } \\
\text { Morais }\end{array}$ & $\begin{array}{l}\text { Universidade Estadual } \\
\text { da Paraíba }\end{array}$ & 2018 \\
\hline 29 & $\begin{array}{l}\text { Desenvolvimento de um } \\
\text { Jogo de Computador } \\
\text { Educacional de } \\
\text { Matemática - o Mestre } \\
\text { de Trigonometria }\end{array}$ & $\begin{array}{l}\text { Matemática em Rede } \\
\text { Nacional }\end{array}$ & $\begin{array}{l}\text { SILVA, Hamilcar } \\
\text { Pereira da. }\end{array}$ & $\begin{array}{l}\text { Universidade Federal } \\
\text { Rural do Rio de Janeiro }\end{array}$ & 2018 \\
\hline 30 & $\begin{array}{l}\text { O uso de Jogos Digitais } \\
\text { como Ferramenta } \\
\text { Auxiliar no Ensino da } \\
\text { Matemática e o } \\
\text { Protótipo do Game } \\
\text { Sinaps }\end{array}$ & $\begin{array}{l}\text { Matemática em Rede } \\
\text { Nacional }\end{array}$ & $\begin{array}{l}\text { SIENA, Mauro } \\
\text { Cesar de Souza }\end{array}$ & $\begin{array}{l}\text { Universidade Federal } \\
\text { de Goiás }\end{array}$ & 2018 \\
\hline 31 & $\begin{array}{l}\text { Utilização de Jogos } \\
\text { Sérios na Aprendizagem } \\
\text { de Matemática }\end{array}$ & $\begin{array}{l}\text { Matemática em Rede } \\
\text { Nacional }\end{array}$ & $\begin{array}{l}\text { SANTOS, Sergio } \\
\text { Luis Tamassia } \\
\text { dos. }\end{array}$ & $\begin{array}{l}\text { Universidade de São } \\
\text { Paulo }\end{array}$ & 2018 \\
\hline 32 & $\begin{array}{l}\text { Mundo Virtual Minecraft: } \\
\text { um Contexto de } \\
\text { Aprendizagens de } \\
\text { Conceitos Geométricos }\end{array}$ & $\begin{array}{l}\text { Ensino de Ciências e } \\
\text { Matemática }\end{array}$ & $\begin{array}{l}\text { SILVA, Ana Lucia } \\
\text { da. }\end{array}$ & $\begin{array}{l}\text { Universidade Estadual } \\
\text { da Paraíba }\end{array}$ & 2018 \\
\hline 33 & $\begin{array}{l}\text { Jogos Digitais e } \\
\text { Probabilidades: Uma } \\
\text { Possibilidade de Ensino }\end{array}$ & $\begin{array}{l}\text { Modelagem } \\
\text { Matemática e } \\
\text { Computacional } \\
\end{array}$ & $\begin{array}{l}\text { NASCIMENTO, } \\
\text { Josevandro Barros }\end{array}$ & $\begin{array}{l}\text { Universidade Federal } \\
\text { da Paraíba }\end{array}$ & 2018 \\
\hline
\end{tabular}




\begin{tabular}{|c|c|c|c|c|c|}
\hline & Interdisciplinar & & & & \\
\hline 34 & $\begin{array}{l}\text { Handles - a Trajetória } \\
\text { de Desenvolvimento de } \\
\text { um Jogo Digital para } \\
\text { Ensino de Matemática }\end{array}$ & $\begin{array}{l}\text { Educação para a } \\
\text { Ciência }\end{array}$ & $\begin{array}{l}\text { SILVA, Marcos } \\
\text { Henrique de Paula } \\
\text { Dias da. }\end{array}$ & $\begin{array}{l}\text { Universidade Estadual } \\
\text { Paulista Júlio de } \\
\text { Mesquita Filho }\end{array}$ & 2018 \\
\hline 35 & $\begin{array}{l}\text { A Integração do Jogo } \\
\text { Digital Saga Linear na } \\
\text { Situação-problema com } \\
\text { Regressão Linear sob a } \\
\text { Ótica da Modelagem } \\
\text { Matemática }\end{array}$ & Educação Matemática & $\begin{array}{l}\text { GOES, Luis } \\
\text { Eduardo Silva. }\end{array}$ & $\begin{array}{l}\text { Universidade Estadual } \\
\text { de Santa Cruz }\end{array}$ & 2018 \\
\hline 36 & $\begin{array}{l}\text { Os Jogos Digitais como } \\
\text { Qualificadores da } \\
\text { Aprendizagem de } \\
\text { Frações }\end{array}$ & $\begin{array}{l}\text { Ensino de Ciências e } \\
\text { Matemática }\end{array}$ & $\begin{array}{l}\text { BOSZKO, } \\
\text { Leandro. }\end{array}$ & $\begin{array}{l}\text { Fundação Universidade } \\
\text { de Passo Fundo }\end{array}$ & 2018 \\
\hline 37 & $\begin{array}{l}\text { A Tecnologia } \\
\text { Educacional no Ensino } \\
\text { da Geometria: Jogos } \\
\text { Digitais }\end{array}$ & $\begin{array}{l}\text { Ensino Cientifico e } \\
\text { Tecnológico }\end{array}$ & $\begin{array}{l}\text { TIZIAM, Andre } \\
\text { Luiz. }\end{array}$ & $\begin{array}{l}\text { Universidade Regional } \\
\text { Integrada do Alto } \\
\text { Uruguai e das Missões }\end{array}$ & 2018 \\
\hline 38 & $\begin{array}{l}\text { Jogos Digitais no Ensino } \\
\text { da Matemática: uma } \\
\text { Intervenção } \\
\text { Colaborativa no } \\
\text { Laboratório de } \\
\text { Informática }\end{array}$ & $\begin{array}{l}\text { Metodologias para o } \\
\text { Ensino de Linguagens } \\
\text { e suas Tecnologias }\end{array}$ & $\begin{array}{l}\text { KIRNEW, Lisandra } \\
\text { Costa Pereira }\end{array}$ & $\begin{array}{l}\text { Universidade Norte do } \\
\text { Paraná }\end{array}$ & 2018 \\
\hline 39 & $\begin{array}{l}\text { Jogos de Computador } \\
\text { no Ensino de } \\
\text { Matemática }\end{array}$ & $\begin{array}{l}\text { Matemática em Rede } \\
\text { Nacional }\end{array}$ & $\begin{array}{l}\text { FONSECA, Jose } \\
\text { Magno dos Santos }\end{array}$ & $\begin{array}{l}\text { Universidade Federal } \\
\text { de Viçosa }\end{array}$ & 2018 \\
\hline
\end{tabular}

Fonte: elaborado pelos próprios autores.

Diante do número expressivo de dissertações encontradas, torna-se necessário sintetizar as informações referentes aos traços de game design descritos nas dissertações. Não perdendo de vista o objetivo deste trabalho, em identificar as manifestações de game design nas pesquisas acadêmicas, é possível organizar estes trabalhos basicamente em quatro categorias, de A até D. O Quadro 3 sintetiza esta categorização.

\section{Quadro 3: Categorias das manifestações de game design nas dissertações que} relacionam jogos digitais e matemática.

\begin{tabular}{|c|c|c|c|}
\hline Grupo & Categorias & $\begin{array}{l}\text { Dissertações } \\
\text { (ID) }\end{array}$ & $\begin{array}{c}\text { Traços de game } \\
\text { design }\end{array}$ \\
\hline A & $\begin{array}{l}\text { Há desenvolvimento de jogos digitais, por } \\
\text { software, com discussões dos elementos básicos } \\
\text { que constituem o game design por Schell (2008) } \\
\text { ou próximas tais ideias, como foco no } \\
\text { desenvolvimento da aprendizagem em } \\
\text { matemática. }\end{array}$ & $\begin{array}{c}1,3,6,10,14,15 \\
17,18,29,30,33 \\
34,35 \text { е } 37\end{array}$ & $\begin{array}{l}\text { Predomínio dos } \\
\text { elementos: } \\
\text { "Mecânica" e } \\
\text { "Tecnologia", de } \\
\text { game design. }\end{array}$ \\
\hline B & $\begin{array}{l}\text { Utilizam jogos já prontos. Apesar de constar, } \\
\text { em alguns momentos, apontamento da } \\
\text { contribuição da existência de elementos de game } \\
\text { design no processo de aprendizagem da } \\
\text { matemática, mas não é foco de discussão a } \\
\text { criação desses itens de design. }\end{array}$ & $\begin{array}{c}2,5,9,11,12,19 \\
20,22,23,24,32 \\
36,38 \text { e } 39\end{array}$ & $\begin{array}{l}\text { Apresenta melhor } \\
\text { reflexão dos } \\
\text { elementos de } \\
\text { game design. }\end{array}$ \\
\hline C & $\begin{array}{l}\text { Utilizam software de criação de jogos digitais, } \\
\text { porém sem uma discussão ou reflexão nos } \\
\text { elementos de game design de forma explícita. } \\
\text { Contudo, mantêm a preocupação com a } \\
\text { aprendizagem em matemática. }\end{array}$ & $4,16,25$ e 27 & $\begin{array}{l}\text { Há traços de } \\
\text { game design, } \\
\text { porém de maneira } \\
\text { implícita. }\end{array}$ \\
\hline
\end{tabular}




\begin{tabular}{|c|l|c|c|}
\hline D & $\begin{array}{l}\text { Somente tratamento do tema jogos digitais e } \\
\text { suas contribuições para a aprendizagem em } \\
\text { matemática. Não há presença de discussão de } \\
\text { game design }\end{array}$ & $7,8,13,21,26$, & $\begin{array}{c}\text { Sugere (implícita) } \\
\text { a preocupação } \\
\text { com a mecânica e } \\
\text { a tecnologia. }\end{array}$ \\
\hline
\end{tabular}

Fonte: elaborado pelos próprios autores.

No grupo A, encontram-se as dissertações por principais traços que sugerem a presença e discussões acerca de game design, à luz dos quatros elementos básicos definidos por Schell (2008). No entanto, nessas pesquisas, nem sempre todos esses elementos caminham juntos ou existe predominância de determinados elementos básicos de game design. No grupo B, foram separadas as pesquisas que se utilizaram de jogos prontos para realizar a investigação. Nessa categoria o que se observa é que são discutidos, muitas vezes de forma implícita, como os elementos de game design contribuem no processo do desenvolvimento da aprendizagem de matemática, porém os aspectos de game design são observados a posteriori, sobre jogos prontos. No grupo C, por sua vez, estão os trabalhos que, apesar de utilizarem softwares de criação de jogos, não destacam reflexões sobre os elementos de game design. E por fim, no grupo $D$, não há presença de qualquer discussão na perspectiva de game design. Para classificação das dissertações, foi realizada a leitura dos respectivos resumos, precisando ampliar muitas vezes a leitura para outras partes dos textos.

Diante isso, observa-se que há mais publicações que apresentam manifestações de elementos de game design do que as que sequer tratam desses traços ou, simplesmente, os tangenciam. Vale ressaltar que diante da leitura dessas publicações, em relação às que tratam de game design, nota-se considerável frequência de traços que remetem aos elementos da Mecânica e Tecnologia, conforme mencionada por Schell (2008). Quanto aos aspectos de Narrativa e Estética, estes acabam recebendo menos atenção durante o desenvolvimento de jogos ou no processo de identificação das potencialidades dos jogos digitais para contribuições da aprendizagem em matemática.

\section{Considerações Finais}

Este trabalho buscou apresentar um estudo do tipo Estado da Arte ou do Conhecimento sobre pesquisas acadêmicas (teses e dissertações), produzidas no Brasil, para investigar o que emerge de game design nessas produções, na relação entre jogos digitais e a matemática, no período de 2008 a 2018. Devido aos avanços recentes das tecnologias digitais, esse período demonstra favorável para integração dos jogos digitais nas práticas escolares. No entanto, nota-se a timidez de pesquisas, em especial as teses de doutorado, que tenham foco nessa temática de integração de game design e a Matemática.

Diante do exposto nos resultados e análises, pode-se pensar que 0 desenvolvimento ou criação de jogos digitais para fins educacionais muitas vezes não considera todos os elementos do game design. Nesse sentido, nota-se a emergência de repensar o processo de desenvolvimento de jogos digitais educacionais, em especial, para contribuir no desenvolvimento da aprendizagem em matemática, integrando os 
elementos de game design: a Mecânica, a Narrativa, a Estética e a Tecnologia, sugeridos por Schell (2008), todos eles com a mesma importância.

Além disso, é importante considerar que valorizar a integração de jogos digitais no processo educacional demonstra considerar o perfil das atuais gerações de alunos e as demandas da contemporaneidade, bem como os significados e contribuições que, em especial, a matemática pode trazer para o desenvolvimento de habilidades essenciais para a formação de um cidadão atuante na sociedade e capaz de elaborar e dar seguimento a seu projeto de vida. Para concluir, é possível perceber que todas as pesquisas demonstram o potencial da relação entre jogos digitais e suas contribuições no desenvolvimento da aprendizagem em matemática. Ainda, para Rosa, Almeida e Dezordi (2017) utilizar os jogos como uma estratégia de ensino pode valorizar o trabalho em equipe e procura resgatar valores éticos e de convívio harmonioso no âmbito das escolas, e valorizar o que o ser humano tem de mais valioso, que é a vida.

\section{Referências}

ADAMOWICZ, B. E. Um Jogo Computacional como Proposta para o Estudo de Funções. 2015. 110 f. Dissertação (Mestrado em Ensino de Ciência e Tecnologia). Universidade Tecnológica Federal do Paraná. Ponta Grossa - PR. 2015.

ARAÚJO, F. F. N. Os Games e as Funções Matemáticas: Uma aplicabilidade do Tribal Wars no cotidiano escolar do Ensino Médio. 2010. 142 f. Dissertação (Mestrado Profissional em Ensino de Ciências e Matemática). Universidade Estadual da Paraíba UEPB. Campina Grande - PB. 2010.

AZEVEDO, G. T. Construção de Conhecimento Matemático a Partir da Produção de Jogos Digitais em Um Ambiente Construcionista de Aprendizagem: Possibilidades e Desafios. 2017. 235 f. Dissertação (Mestrado em Ensino e Aprendizagem de Ciências e Matemática). Universidade Federal de Goiás. Goiânia - GO. 2017.

BAIROS, M. G. Matemática, internet e jogos de lógica, uma combinação possível. 2014. 17 f. Dissertação (Mestrado Profissional em Matemática). Universidade Federal de São João del-Rei - UFSJ. 2014.

BARBOZA JR, A. T.; SILVEIRA, I. F. PerMotivE: Um Modelo conceitual de Persuasão, Motivação e Engajamento para Jogos Educacionais. XV Simpósio Brasileiro de Jogos Digitais e Entretenimento (SBGAMES), São Paulo, p. 920-929, 2016.

BARCELOS, T. S. Relações entre o Pensamento Computacional e a Matemática em atividades didáticas de construção de jogos digitais. Tese de Doutorado em Ensino de Ciências e Matemática. Universidade Cruzeiro do Sul, São Paulo, 2014.

BERNSTEIN, T. C. Ensino de Matemática e Jogos Digitais: um estudo Etnomatemático nos anos iniciais. 2017. 131 f. Dissertação (Mestrado Profissional em Ensino de Ciências Exatas). Centro Universitário UNIVATES. Lajeado. 2017.

BOSZKO, L. Os Jogos Digitais como Qualificadores da Aprendizagem de Frações. 2018. 67 f. Dissertação (Mestrado em Ensino de Ciências e Matemática). Universidade de Passo Fundo. Passo Fundo. 2018. 
BRASIL, Ministério da Educação/CONSED/UNDIME. Base Nacional Comum Curricular. Versão Final. 2017. Disponível em <http://basenacionalcomum.mec.gov.br/wpcontent/uploads/2018/06/BNCC_EI_EF_110518_versaofinal_site.pdf> Acessado em 12 out. 2018.

BRITO, A. S. Jogos Pedagógicos Digitais na Formação Inicial de Professores que ensinam matemática nas séries iniciais do Ensino Fundamental. 2016. $113 \mathrm{f}$. Dissertação (Mestrado em Ensino de Ciências e Matemática). Universidade Cruzeiro do Sul. São Paulo - SP. 2016

CAMPANA, S. B. C. Transposição de Jogos de Tabuleiro Utilizados no Ensino de Matemática para o Formato Digital. 2017. 119 f. Dissertação (Mestrado em Mídia e Tecnologia). Universidade Estadual Paulista - UNESP. Bauru - SP. 2017.

CARVALHO, C. H. S. Jogos Digitais e o Ensino de Matemática a Partir dos Estilos de Aprendizagem de Felder. 2016. 96f. Dissertação (Mestrado em Ciências e Tecnologias na Educação. Instituto Federal Sul-Rio-Grandense. Pelotas - RS. 2016.

CAVALCANTE, M. T. M. O Ensino de Matemática, a Neurociência e os Games: Desafios e Possibilidades. 2018. 104 f. Dissertação (Mestrado em Ensino de Ciências e Educação Matemática). Universidade Estadual da Paraíba. Campina Grande - PB. 2018.

FARIAS, R. A. Análise do Currículo e o Uso de Jogos Online durante o Processo de Ensino-Aprendizagem, em ciências e Matemática, nos anos iniciais do Ensino Fundamental. 2017. 97 f. Dissertação (Mestrado em Ensino de Ciências). Universidade Cruzeiro do Sul. São Paulo - SP. 2017.

FERREIRA, A. P. Q. "Avançando com a Matemática!": Um jogo computacional para alunos do Quinto ano do Ensino Fundamental. 139 f. 2016. Dissertação (Mestrado em Ensino das Ciências na Educação Básica). Universidade do Grande Rio "Prof. José de Souza Herdy" - UNIGRANRIO. Duque de Caxias - RJ. 2016.

FLORET, H. F. Jogos Eletrônicos Gratuitos para o Ensino da Matemática: Levantamento e Proposta de um Recurso Didático. 2013. 162 f. Dissertação (Mestrado em Ensino de Ciências na Educação Básica. Universidade do Grande Rio "Prof. José de Souza Herdy". Duque de Caxias - RJ. 2013.

FONSECA, J. M. S. Jogos de Computador no Ensino de Matemática. 2018. 44 f. Dissertação (Mestrado Profissional em Matemática). Universidade Federal de Viçosa. Florestal - MG. 2018.

GAMA, R. F. Uso dos Jogos Digitais como Artefatos para o Ensino de Função do Primeiro e Segundo Graus. 2016. 79 f. Dissertação (Mestrado em Ensino de Ciências e Matemática. Universidade Federal de Pelotas. Pelotas - RS. 2016.

GOES, L. E. S. A Integração do Jogo Digital Sala Linear na Situação-Problema com Regressão Linear sob a Ótica da Modelagem Matemática. 2018. 106 f. Dissertação (Mestrado em Educação Matemática). Universidade Estadual de Santa Cruz. Ilhéus - BA. 2018.

GOMES, L. A. F. Aplicativos do Sistema Operacional Android na Aprendizagem de Matemática: Aplicativos e Jogos Digitais. 2017. 117 f. Dissertação (Mestrado em 
Educação Matemática). Universidade Estadual da Paraíba. 2018. Campina Grande - PB. 2017.

GRIS, G. Desenvolvimento e Avaliação de um Jogo de Dominó Digital Adaptado para Ensino de Relações Condicionais Matemáticas. 2016. 118 f. Dissertação (Mestrado em Análise do Comportamento). Universidade Estadual de Londrina - PR. 2016.

IANAGUIVARA, E. S. Método de Concepção de Serious Game para Avaliar Conceitos Básicos de Matemática de Alunos com Falta de Atenção. Tese de doutorado em Engenharia Biomédica - Universidade de Mogi das Cruzes, Mogi das Cruzes - SP, 2016.

JUSTO, A. O. R. P. Ensino de Estatística por meio de Jogos. 2017. 123 f. Dissertação (Mestrado Profissional no Ensino de Matemática). Universidade de São Paulo. São Paulo - SP. 2017.

KIRNEW, L. C. P. Jogos Digitais no Ensino da Matemática: uma intervenção colaborativa no laboratório de informática. 2048. 116 f. Dissertação (Mestrado em Metodologias para o Ensino de Linguagens e suas Tecnologias). Universidade Pitágoras Unopar. Londrina - PR. 2018

KIRRIEMUIR, John; MCFARLANE, Angela. Literature Review in Games and Learning. A NESTA Futurelab Research report - report 8. 2004. <hal-00190453>. Disponível em < https://telearn.archives-ouvertes.fr/hal-00190453/document> Acesso em 17 nov. 2018.

LEITE, P. S.; MENDONÇA, V. G. Diretrizes para Game Design de Jogos Educacionais. SBC - Proceedings of SBGames 2013. Disponível em < http://www.sbgames.org/sbgames2013/proceedings/artedesign/17-dt-paper.pdf> Acesso em 23 abr. 2018.

MARCONI, M. A; LAKATO, E. M. Fundamentos de Metodologia Científica. 7. ed. São Paulo: Atlas, 2010.

MARINHO, F. C. V. Saberes Docentes para Promoção de Aprendizagem em Ciências e Matemática a partir do Desenvolvimento de Jogos Digitais. Tese de Doutorado em Educação em Ciências e Saúde. Universidade Federal do Rio de Janeiro, 2014.

MASCIANO, C. F. R. O uso de jogos do software educativo Hércules e Jiló no mundo da matemática na construção do conceito de número por estudantes com deficiência intelectual. 2015. 179 f. Dissertação (Mestre em Educação). Universidade de Brasília. 2015.

MAZIVIERO, H. F. G. Jogos Digitais no Ensino de Matemática - O Desenvolvimento de um Instrumento de Apoio ao Diagnóstico das Concepções dos Alunos sobre Diferentes Representações dos Números. 2014. 119 f. Dissertação (Mestrado em Educação para a Ciência). Universidade Estadual Paulista "Júlio de Mesquita Filho" - UNESP. Bauru - SP. 2014.

MOYSÉS, L. Aplicações de Vygotsky à educação matemática. Campinas, SP: Papirus, 1997. $4^{\mathrm{a}}$ ed. 2001. 
NASCIMENTO, J. B. Jogos Digitais e Probabilidades: uma possibilidade de ensino interdisciplinar. 2018. 90 f. Dissertação (Mestrado em Modelagem Matemática e Computacional). Universidade Federal da Paraíba. João Pessoa - PB. 2018

NASCIMENTO, T. S. X. Critérios de Decisão e Games em Sala de Aula. 2017. 116 f. Dissertação (Mestrado em Ensino de Ciências e Matemática). Universidade Estadual de Campinas. Campinas. 2017.

NUNES, M. S. V. Elaboração e Desenvolvimento de Jogo Matemático para aplicações WEB Mobile como Auxilio dos Processos EA da Matemática Financeira. 2017. Dissertação (Mestrado em Computação Aplicada). Universidade Estadual do Ceará. 2017.

OECD (2013). PISA 2012 Assessment and Analytical Framework: Mathematics, Reading, Science, Problem Solving and Financial Literacy. OECD Publishing. http://dx.doi.org/10.1787/9789264190511-en

PEREIRA, A. B. C. Uso de Jogos Digitais no Desenvolvimento de Competências Curriculares da Matemática. Tese de Doutorado em Ciências da Computação Universidade de São Paulo, São Paulo, 2017.

PEREIRA, R. S. G. et al. Modelagem Matemática e Tecnologias Digitais Educacionais: Possibilidades e Aproximações por meio de uma Revisão Sistemática de Literatura. REnCiMa, v.8, n.2, p.80-94, 2017.

PETRY, L. C. O conceito ontológico de jogo. In: ALVES, V.; COUTINHO, I. J. (orgs.). Jogos digitais e aprendizagem: fundamentos para uma prática baseada em evidências. Campinas, SP: Papirus, 2016.

PINHEIRO, P. G. R. Criação e Adaptação de Jogos para o Geogebra. 2017. 105 f. Dissertação (Mestrado Profissional em Matemática). Universidade Federal dos Vales do Jequitinhonha e Mucuri. Teófilo Otoni. 2017.

POLONIO, R. J. D. O processo de criação de um jogo com o auxílio de recursos computacionais que relaciona progressões aritméticas e funções lineares. 2015. 39 f. Dissertação (Mestrado Profissional em Matemática). Instituto de Ciências Matemáticas e de Computação -ICMC-USP. São Carlos - SP. 2015.

ROSA, L. Z.; ALMEIDA, C. G. M.; DEZORDI, F. Z. RPGBIO DROGADIÇÃO: O JOGO ROLE PLAYING GAME (RPG) COMO PRÁTICA NO PROCESSO DE ENSINO E APRENDIZAGEM. REnCiMa, v.8, n.1, p.166-181, 2017.

SANTOS, S. L. T. Utilização de Jogos Sérios na Aprendizagem de Matemática. 2018. 136 f. Dissertação (Mestrado Profissional em Matemática). Instituto de Ciências Matemáticas e de Computação - ICMC-USP. São Paulo-SP. 2018.

SCHELL, J. The Art of Game Design: A Book of Lenses. Burlington - USA. Elsevier, 2008.

SCHLEMMER, E.; LOPES, D. Q. Avaliação de aprendizagem em processos gamificados: desafios para apropriação do método cartográfico. In: ALVES, V.; COUTINHO, I. J. (orgs.). Jogos digitais e aprendizagem: fundamentos para uma prática baseada em evidências. Campinas, SP: Papirus, 2016. 
SIENA, M. C. S. O Uso de Jogos Digitais como Ferramenta Auxiliar no Ensino da Matemática e o Protótipo do Game Sinapsis. 2018. 101 f. Dissertação (Mestrado em Matemática). Universidade Federal de Goiás. Goiânia - GO. 2018.

SILVA, A. L. Mundo Virtual Minecraft: um contexto de aprendizagens de conceitos geométricos. 2018. 116 f. Dissertação (Mestrado Profissional em Ensino de Ciências e Matemática). Universidade Estadual da Paraíba. Campina Grande - PB. 2018.

SILVA, H. P. Desenvolvimento de um Jogo de Computador Educacional de Matemática - O Mestre de Trigonometria. 2018. 93 f. Dissertação (Mestrado Profissional em Matemática). Universidade Federal Rural do Rio de Janeiro. Seropédica RJ. 2018

SILVA, H. W. Estudo sobre as Potencialidades do Jogo Digital Minecraft para o Ensino de Proporcionalidade e Tópicos de Geometria. 2017. 113 f. Dissertação (Mestrado em Educação Matemática). Pontifícia Universidade Católica de São Paulo. São Paulo - SP. 2017.

SILVA, J. C. M. O Uso de Software de Autoria JCLIC como Ferramenta Pedagógica no Processo de Ensino-Aprendizagem de Conteúdos da Matemática nas Séries Finais do Ensino fundamental por Meio da Construção de Jogos Educativos. 2013. 112 f. Dissertação (Mestrado em Ensino de Ciências e Matemática) - Universidade Federal do Ceará. Fortaleza - CE. 2013.

SILVA, J. C. PRODUÇÃO DE JOGOS DIGITAIS POR JOVENS: Uma possibilidade de Interação com a Matemática. Tese de Doutorado em Educação. Universidade Federal de Uberlândia. Uberlândia, 2016.

SILVA, M. H. P. D. Handles - a trajetória de desenvolvimento de um jogo digital para ensino de Matemática. 2018. 182 f. Dissertação (Mestrado em Educação para a Ciência). Universidade Estadual Paulista "Júlio de Mesquita Filho" - UNESP. Bauru-SP. 2018.

SILVA, S. L. D. A Interatividade dos Jogos Digitais na Aprendizagem Matemática: uma Discussão em Neurociência. 2017. 120 f. Dissertação (Mestrado em Educação) Universidade Federal da Fronteira Sul. Erechim - RS. 2017.

SILVEIRA, I. F.; VILLALBA-CONDORI, K. O. An Open Perspective for Educational Games. Journal of Information Technology Research (JITR), v. 11, n. 1, p. 18-28, 2018.

SOUZA JR., M. B. As contribuições da Construção de Jogos Eletrônicos para a Formação Matemático-Pedagógica-Tecnológica de Professores das Séries Iniciais do Ensino Fundamental. 2010. 96 f. Dissertação (Mestre em Ensino de Ciências e Matemática) - Universidade Luterana do Brasil, Canoas - RS, 2010.

TATAGIGA, J. S. Jogos Digitais Educativos e o Ensino da Matemática: diferentes olhares e experiências. 2017. 119 f. Dissertação (Mestrado em Educação). Universidade do Estado do Rio de Janeiro. Rio de Janeiro. 2017. 
TIZIAM, A. L. A Tecnologia Educacional no Ensino da Geometria: Jogos Digitais. 2018. 101 f. Dissertação (Mestrado em Ensino Científico e Tecnológico. Universidade Regional Integrada do Alto Uruguai e das Missões - URI. Santo Ângelo. 2018.

TONÉIS, Cristiano Natal. A Lógica da Descoberta nos Jogos Digitais. 2010. $162 \mathrm{f}$. Dissertação (Mestre em Tecnologias da Inteligência e Design Digital) - Pontifícia Universidade Católica de São Paulo, São Paulo, 2010.

TONÉIS, Cristiano Natal. A Experiência Matemática no Universo dos Jogos Digitais: O processo do jogar e o raciocínio lógico e matemático. 2015. 128f. Tese (Doutorado em Educação Matemática) - Universidade Anhanguera de São Paulo, São Paulo, 2015. 